\title{
Clinical analysis of treatment strategies to cholecystocholedocholithiasis patients with previous subtotal or total gastrectomy: a retrospective cohort study
}

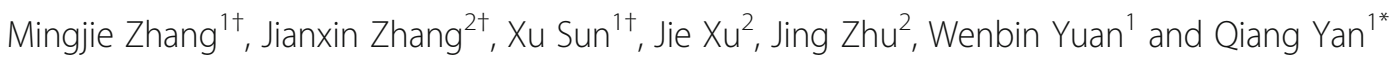

\begin{abstract}
Background: Previous gastrectomy can lead to an increased incidence of cholecystocholedocholithiasis (CCL) and increased morbidity rate. However, the appropriate treatment strategy for patients with $C C L$ and a history of gastrectomy remains unclear.

Methods: We performed a retrospective cohort study of patients with $C C L$ and a history of gastrectomy who underwent either one-stage laparoscopic common bile duct (CBD) exploration with stone clearance and laparoscopic cholecystectomy (LCBDE+LC) or two-stage endoscopic retrograde cholangiopancreatography followed by LC (ERCP+LC) from May 2010 to March 2018.

Results: The success rate of ERCP for CBD stone clearance was $81.2 \%$ in patients with a history of Billroth I gastrectomy and $23.7 \%$ in patients with a history of Billroth $\|$ or Roux-en-Y esophagojejunostomy $\left[X^{2}=97.67, P<0.001\right.$, risk ratio $(R R)=3.43]$. The success rate of second-step $L C$ after successful ERCP for removal of CBD stones and the success rate of $\mathrm{LCBDE}+\mathrm{LC}$ after ERCP treatment failure were 96.8 and $87.7 \%$, respectively, in patients with preoperative intra-abdominal adhesion evaluation scores of $\leq 3$ points. These success rates were 28.6 and $27.6 \%$, respectively, in patients with scores of $>3$ points $\left(X^{2}=59.70, P<0.001, R R=3.38\right.$ and $X^{2}=53.41, P<0.001, R R=3.27$, respectively).

Conclusions: Based on the results of this study, ERCP $+L C$ seems to be an attractive strategy for treatment of $C C L$ in patients with a history of Billroth I gastrectomy, and LCBDE+LC appears to be suitable for patients with a history of Billroth II or Roux-en-Y esophagojejunostomy. Preoperative evaluation of intra-abdominal adhesions helps to reduce the conversion rate of laparoscopic surgery.
\end{abstract}

Keywords: Cholecystocholedocholithiasis, Laparoscopic common bile duct exploration, Laparoscopic cholecystectomy, Endoscopic retrograde cholangiopancreatography, Previous gastrectomy

\section{Background}

Treatment options for cholecystocholedocholithiasis (CCL) include two-stage endoscopic retrograde cholangiopancreatography (ERCP) followed by laparoscopic cholecystectomy (LC) (i.e., ERCP+LC), one-stage laparoscopic common bile duct exploration (CBDE) and LC (i.e., LCBDE+LC), and laparotomic CBDE and cholecystectomy [1,2]. With the

\footnotetext{
* Correspondence: yanqiangdoc@hotmail.com

${ }^{+}$Mingjie Zhang, Jianxin Zhang and Xu Sun contributed equally to this work.

1 Department of Hepatobiliary surgery, Huzhou Hospital, Zhejiang University

School of Medicine (Huzhou Central Hospital), No. 198, Hongqi Road,

Huzhou 313000, Zhejiang Province, China

Full list of author information is available at the end of the article
}

development of laparoscopic and endoscopic equipment and technology, open CBDE is now rarely applied in clinical practice [3]. However, whether ERCP+LC or LCBDE $+\mathrm{LC}$ is more beneficial in the management of patients with CCL remains unclear [4]. Patients with a history of gastrectomy have a higher incidence of CCL and morbidities requiring surgical treatment $[5,6]$. The therapeutic strategy for CCL in patients with a history of gastrectomy is still being debated. This study was performed to investigate the correlative factors that influence the option of treatment modalities to allow for the development of individualized

(c) The Author(s). 2018 Open Access This article is distributed under the terms of the Creative Commons Attribution 4.0 International License (http://creativecommons.org/licenses/by/4.0/), which permits unrestricted use, distribution, and reproduction in any medium, provided you give appropriate credit to the original author(s) and the source, provide a link to the Creative Commons license, and indicate if changes were made. The Creative Commons Public Domain Dedication waiver (http://creativecommons.org/publicdomain/zero/1.0/) applies to the data made available in this article, unless otherwise stated. 
treatment strategies for patients with CCL and a history of gastrectomy.

\section{Methods}

\section{Study protocol}

We performed a retrospective cohort study of patients with CCL and a history of gastrectomy in Huzhou Central Hospital and the No. 3 People's Hospital of Changxing County, China from May 2010 to March 2018. In all patients, the diagnosis of CCL was confirmed by magnetic resonance cholangiopancreatography. The study was approved by both hospitals' ethics committees, and written informed consent was obtained from each patient. Both hospitals provide a comprehensive general surgical service and tertiary care for patients undergoing hepatobiliary surgery among a population of 3 million people. In total, 394 consecutive patients were enrolled in this study. Of these, 342 patients underwent ERCP for removal of CBD stones first, and 289 patients who were candidates for elective LC or $\mathrm{LCBDE}+\mathrm{LC}$ underwent preoperative evaluation of intra-abdominal adhesions based on our previous research [7], as shown in Table 1. All ERCP procedures were performed by senior endoscopists familiar with the procedure. The patients underwent endoscopic sphincterotomy and clearance of CBD stones with a balloon or Dormia basket. Laser lithotripsy was not available. A plastic stent was introduced for patients with retained CBD stones after primary ERCP clearance. All laparoscopic operations in both departments were performed by consultant surgeons. The technique of LC or LCBDE for treatment of CCL in patients with a history of gastrectomy has been described in our previous publications $[7,8]$. The clinical outcomes of each CCL management technique were documented.

\section{Statistical analysis}

All data were prepared and compiled using the SPSS computer program (version 19.0 for Windows; IBM

Table 1 Evaluation score table of preoperative intraabdominal adhesions

\begin{tabular}{lll}
\hline \multicolumn{3}{l}{ Score (points) } \\
\hline $\begin{array}{l}\text { Hyperplasia of original } \\
\text { incision }\end{array}$ & No (0) & Yes (1) \\
$\begin{array}{l}\text { Postoperative intestinal } \\
\text { obstruction }\end{array}$ & No (0) & Yes (1) \\
$\begin{array}{l}\text { Abdominal infection } \\
\text { Methods of } \\
\text { gastroenterostomy }\end{array}$ & No (0) & Yes (1) \\
$\begin{array}{l}\text { Preoperative } \\
\text { ultrasonography test }(0)\end{array}$ & $\begin{array}{l}\text { Billroth II or Roux- } \\
\text { en-Y (1) }\end{array}$ \\
& Lateral MD $>1 \mathrm{~cm}$ & Lateral MD $<1 \mathrm{~cm}$ \\
& Longitudinal MD $>$ & $\begin{array}{l}\text { Longitudinal MD }< \\
\text { cm }\end{array}$ \\
& $3 \mathrm{~cm}$ & (2) \\
\hline
\end{tabular}

MD Movement distance
Corp., Armonk, NY, USA). The chi square test and Fisher's exact test were used for quantitative data. Step-wise regression was used for multivariate analysis to identify any confounding factors. Pearson's correlation test was used for correlation analysis. A $p$-value $<0.05$ was considered statistically significant.

\section{Results}

\section{Patients' demographic information}

The clinical data of all 394 patients with CCL with a history of gastrectomy who underwent treatment from May 2010 to March 2018 were retrospectively reviewed. The patients' ages ranged from 27 to 81 years (mean, 58 years; median, 47 years). The cohort comprised 156 (39.6\%) men and 238 (60.4\%) women, with a male:female ratio of $0.655: 1.000$. No gallbladder cancer was identified. All patients had previously undergone gastrectomy for either gastric cancer [363 patients $(92.1 \%)$ ] or gastroduodenal ulcers [31 patients (7.9\%)]. The types of gastrectomy were distal gastrectomy in 293 patients [Billroth I gastrectomy in 103 patients (26.1\%) and Billroth II gastrectomy in 190 patients (48.2\%)] and total gastrectomy with Roux-en-Y esophagojejunostomy in 101 patients (25.7\%), as shown in Table 2.

\section{ERCP management in patients with CCL and a history of gastrectomy}

A total of 342 patients with CCL and a history of gastrectomy underwent ERCP for removal of CBD stones first. Of these, 139 patients underwent successful CBD stone clearance with ERCP, and without CBD stones retained which confirmed by postoperative magnetic resonance cholangiopancreatography confirmed that no stones had been retained. Among these 139 patients, 82 had previously undergone Billroth I gastrectomy and 57 had previously undergone Billroth II gastrectomy or Roux-en-Y esophagojejunostomy as shown in Fig. 1. The success rate of ERCP for CBD stone clearance was $81.2 \%$ in patients with a history of Billroth I gastrectomy and $23.7 \%$ in patients with a history of non-Billroth I gastrectomy $\left[x^{2}=97.67, P<0.001\right.$, risk ratio $(R R)=3.43$ ], as shown in Table 3.

\section{Laparoscopic surgery in patients with $\mathrm{CCL}$ and a history of gastrectomy}

A total of 118 patients underwent LC after successful CBD stone removal by ERCP, and 171 patients underwent $\mathrm{LCBDE}+\mathrm{LC}$ after ERCP treatment had failed (Fig. 2). The success rates of $\mathrm{LC}$ and $\mathrm{LCBDE}+\mathrm{LC}$ were 96.8 and $84.7 \%$, respectively, in patients with preoperative intra-abdominal adhesion evaluation scores of $\leq 3$ points and 28.6 and $25.9 \%$, respectively, in patients with scores of $>3$ points $\left(x^{2}=59.70, P<0.001, R R=3.38\right.$ and $X^{2}=53.41, P<0.001, R R=3.27$ ), as shown in Table 4. 
Table 2 Details of previous gastrectomy

\begin{tabular}{llll}
\hline Billroth I $(n=103)$ & Gastric antrum cancer $(n=103)$ & & Gastroduodenal ulcer $(n=0)$ \\
& Stage I & $63(61.2 \%)$ & \\
& Stage II & $40(38.8 \%)$ & Gastroduodenal ulcer $(n=31)$ \\
Gillroth II $(n=190)$ & Gastric antrum cancer $(n=159)$ & & Gastric ulcer \\
& Stage I & $9(5.7 \%)$ & Duodenal ulcer \\
& Stage II & $62(39.0 \%)$ & \\
Stage III & $88(55.3 \%)$ & Gastric cardia cancer $(n=12)$ \\
Roux-en-Y $(n=101)$ & Gastric corpus cancer $(n=89)$ & Stage II \\
& Stage I & $1(1.1 \%)$ & Stage III \\
& Stage II & $46(51.7 \%)$ & \\
\hline
\end{tabular}

\section{Clinical outcomes}

A total of 76 patients underwent ERCP+LC and 79 underwent $\mathrm{LCBDE}+\mathrm{LC}$ for treatment of $\mathrm{CCL}$ after a previous gastrectomy. The hospital costs and length of hospital stay were greater in the ERCP+LC than LCBDE $+\mathrm{LC}$ group $(P<0.05)$. The incidence of postoperative bile leakage, postoperative hemorrhage, postoperative cholangitis, postoperative pancreatitis, residual CBD stones, recurrence of CBD stones, bile duct stricture, and patient death were not significantly different between the two groups $(P>0.05)$ (Table 5$)$.

\section{Discussion}

It is widely accepted that patients with a history of gastrectomy have an increased incidence of CCL and increased morbidities requiring surgery [9]. The exact mechanisms for these observations remain unclear. According to the literature, the complex interaction between sectioning of the nerve supply to the gallbladder and the change in cholecystokinin secretion plays an important role $[10,11]$. In gastric operations, reconstruction of the digestive tract may decrease passage of food through the duodenum, which probably decreases

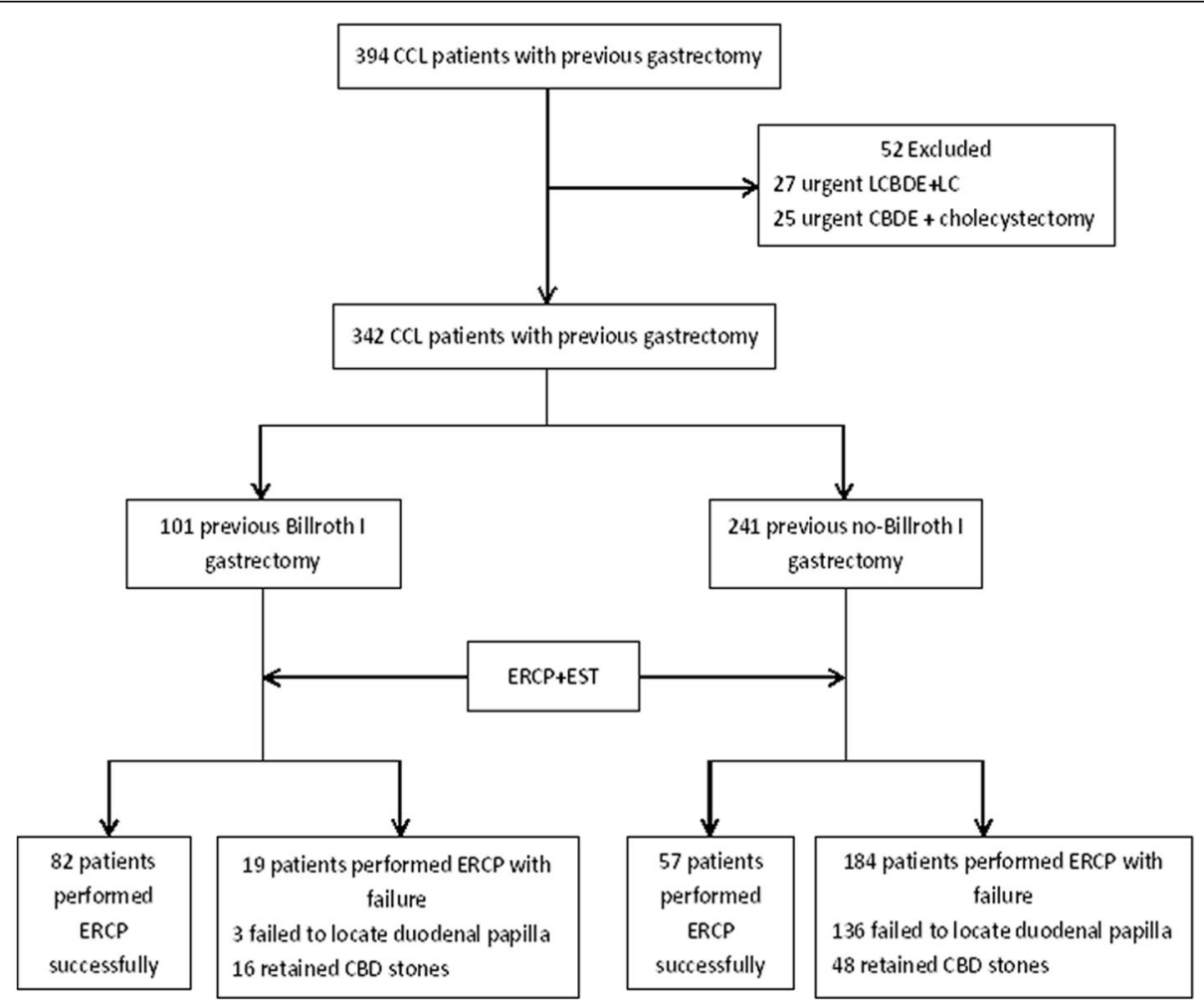

Fig. 1 Flow chart of performing ERCP to CCL patients with previous gastrectomy. CCL: Cholecystocholedocholithiasis; LCBDE: Laparoscopic common bile duct exploration; LC: Laparoscopic cholecystectomy; CBDE: laparotomy common bile duct exploration; ERCP: Endoscopic retrograde cholangiopancreatography; EST: Endoscopic sphincterotomy 
Table 3 Success rate of ERCP for CBD stones clearance in groups with different previous gastrectomy

\begin{tabular}{llllll}
\hline Previous gastrectomy & Total & Success rate of ERCP & $X^{2}$ & $P$ value & \\
\hline Billroth I & 101 & $81.2 \%(82 / 101)$ & 97.67 & 0.001 & $3.43^{\mathrm{a}}$ \\
Non-Billroth I & 241 & $23.7 \%(57 / 241)$ & & \\
\hline
\end{tabular}

${ }_{\mathrm{a} R}=$ Success rate of ERCP in performing Billroth I gastrectomy group / Success rate of ERCP in performing non-Billroth I gastrectomy group $E R C P$ endoscopic retrograde cholangiopancreatography, $C B D$ common bile duct, $R R$ relative risk

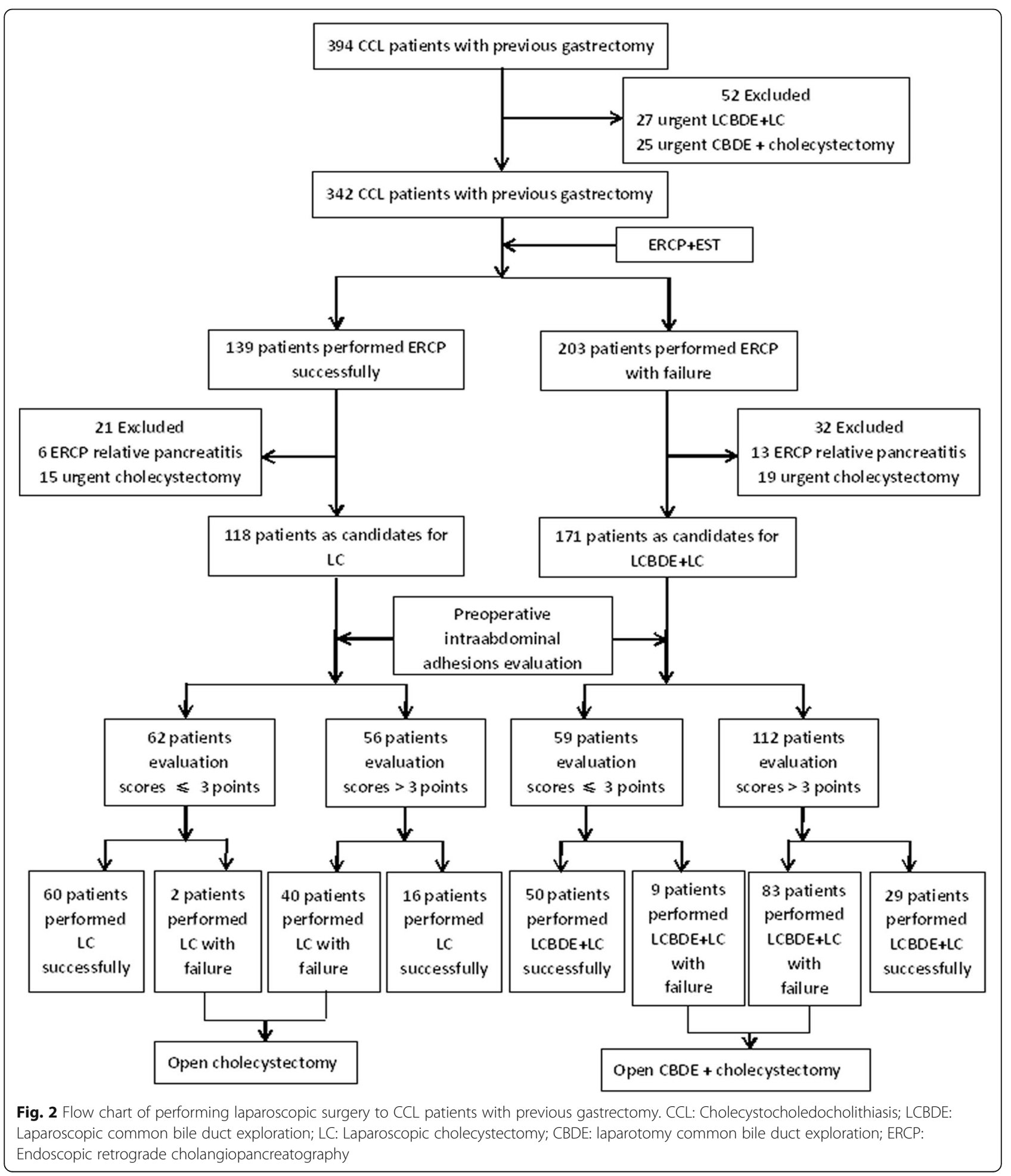


Table 4 Success rate of laparoscopic surgery in CCL patients with previous gastrectomy

\begin{tabular}{|c|c|c|c|c|c|}
\hline Laparoscopic surgery & Preoperative intraabdominal adhesions evaluation scores & Success rate & $x^{2}$ & $P$ value & RR \\
\hline \multirow[t]{2}{*}{$\overline{\mathrm{LC}}(n=118)$} & $\leq 3$ points, $n=62$ & $96.8 \%(60 / 62)$ & 59.70 & 0.001 & $3.38^{\mathrm{a}}$ \\
\hline & $>3$ points, $n=56$ & $28.6 \%(16 / 56)$ & & & \\
\hline \multirow[t]{2}{*}{ LCBDE+LC $(n=171)$} & $\leq 3$ points, $n=59$ & $84.7 \%(50 / 59)$ & 53.41 & 0.001 & $3.27^{\mathrm{b}}$ \\
\hline & $>3$ points, $n=112$ & $25.9 \%(29 / 112)$ & & & \\
\hline
\end{tabular}

${ }^{a} \mathrm{RR}=$ Success rate of LC in evaluation scores $\leq 3$ points group / Success rate of LC in evaluation scores $>3$ points group

${ }^{b} R R=$ Success rate of $L C B D E+L C$ in evaluation scores $\leq 3$ points group / Success rate of $L C B D E+L C$ in evaluation scores $>3$ points group

LC Laparoscopic cholecystectomy, LCBDE Laparoscopic common bile duct exploration

cholecystokinin secretion and reduces gallbladder motility, facilitating gallstone formation [12]. In addition, the hepatic branch of the vagus nerve is unavoidably damaged during surgical operations for gastric cancer because of the need for extended lymphadenectomy; moreover, the absence of or damage to the hepatic branch may cause dysregulation of gallbladder emptying, which may in turn contribute to gallstone formation [13]. Therefore, individualized and appropriate treatment strategies for CCL in patients with a history of gastrectomy are very valuable because such patients are often encountered in clinical practice.

Historically, the treatment of $\mathrm{CCL}$ required open laparotomy and CBDE [14]. After the introduction of ERCP and endoscopic sphincterotomy in the 1970s, $\mathrm{ERCP}+\mathrm{LC}$ provided a less invasive option for treating $\mathrm{CCL}$ and has largely replaced CBDE in the management of CCL in the last two decades $[15,16]$. With the development of laparoscopic equipment and technology, LCBDE has been widely used in clinical practice since its first introduction in 1991 [17-19]. In contrast to $\mathrm{ERCP}+\mathrm{LC}$, which is generally performed in two stages, $\mathrm{LCBDE}+\mathrm{LC}$ for treatment of CCL is generally performed in a single stage. Additionally, this procedure appears to have a shorter hospital stay and similar stone clearance rate, relative cost-effectiveness while preserving the function of the sphincter of Oddi, and fewer ERCP-related complications [20, 21]. Although many studies have proven that $\mathrm{LCBDE}+\mathrm{LC}$ is both feasible and effective in the management of CCL $[22,23]$, one retrospective cohort study performed in the United States showed that the overall use of ERCP+LC for treatment of CCL increased from $52.8 \%$ of admissions in 1998 to $85.7 \%$ in 2013 and that the percentage of patients with CCL undergoing CBDE (including open CBDE and laparoscopic CBDE) decreased from 39.8 to $8.5 \%$ in the same period. These results indicate that despite the potential benefits of $\mathrm{LCBDE}+\mathrm{LC}$ over $\mathrm{ERCP}+\mathrm{LC}$ for managing $\mathrm{CCL}$, the current trends in $\mathrm{CCL}$ management continue, and CBDE may be at risk of disappearing from the surgical armamentarium [24]. Although the results of various studies strongly support this view, which treatment strategy is more beneficial to patients with $\mathrm{CCL}$, especially those with a history of gastrectomy, still needs further investigation.

Most surgical specialists believe that either ERCP+LC or LCBDE+LC should be specifically chosen to treat patients with CCL in clinical practice based on the size and quantity of CBD stones, whether the CBD stones are combined with gallstones, the location and severity of the obstruction, and especially the level of the surgeon's experience in ERCP or LCBDE at individual

Table 5 Clinical outcomes of different management in CCL patients with previous gastrectomy

\begin{tabular}{llll}
\hline Clinical outcomes & $\mathrm{ERCP}+\mathrm{LC}, n=76$ & $\mathrm{LCBDE}+\mathrm{LC}, n=79$ & $P$ value \\
\hline Postoperative bile leakage & $4(5.3 \%)$ & $5(6.3 \%)$ & 0.777 \\
Postoperative hemorrhage & $2(2.7 \%)$ & $4(5.1 \%)$ & 0.433 \\
Postoperative cholangitis & $10(13.2 \%)$ & $6(7.6 \%)$ & 0.255 \\
Postoperative pancreatitis & $8(10.5 \%)$ & $10(12.7 \%)$ & $4(5.1 \%)$ \\
Residual CBD stones $^{\text {a }}$ & $6(7.9 \%)$ & $7(8.9 \%)$ & 0.679 \\
CBD stones recurrence $^{\mathrm{a}}$ & $5(6.6 \%)$ & 0 & 0.473 \\
Bile duct stricture & 0 & $23,162 \pm 89.6$ & 0.595 \\
Hospital costs (RMB) & $37,652 \pm 112.3$ & $6.5 \pm 1.5$ & $0.032^{*}$ \\
Hospital stay (days) & $14.7 \pm 1.8$ & 0 & $0.013^{*}$ \\
Death & 0 & 1.0 \\
\hline
\end{tabular}

$R M B$ (Renminbi) Currency unit of China, ERCP endoscopic retrograde cholangiopancreatography, LC Laparoscopic cholecystectomy, LCBDE Laparoscopic common bile duct exploration, $C B D$ common bile duct

aThe median follow-up time was 37 (range 1-93) months

${ }^{*} p<0.05$ 
treatment centers $[25,26]$. In the two hospitals of the present study, the ERCP technique was introduced in 2001 and has been applied to clinical practice for almost 20 years. Our endoscopists have accumulated abundant experience in performing ERCP to treat CCL, even in patients with a history of gastrectomy, and ERCP is typically the first-line treatment for CCL in both hospitals. We reviewed the clinical data of patients with CCL who underwent ERCP from 2001 to 2018 in our two medical centers and found that a history of gastrectomy was the most common cause of ERCP treatment failure (38.8\%), followed by compact CBD stones (21.3\%) and duodenal papilla hemorrhage (14.2\%). However, the success rate of ERCP in patients with CCL with a history of gastrectomy still reached $67.9 \%$. Previous randomized trials and meta-analyses have demonstrated the safety and efficacy of ERCP management for CCL with a success rate of 61.7 to $94.6 \%$ [27, 28]. Compared with our observation, the success rate of ERCP in patients with CCL and a history of gastrectomy is in accordance with the average level. These results indicate that a history of gastrectomy may be an important reason for failure of ERCP, but not a contraindication. Identification of the risk factors for ERCP failure in patients with CCL and a history of gastrectomy is important and was the major aim of our study. We selected gastroenteric anastomosis as the candidate risk factor and conducted a retrospective cohort study from May 2010 to March 2018, and we found that patients with a history of Billroth I gastrectomy have a higher success rate of ERCP for clearance of CBD stones and that ERCP might therefore be the first choice to treat choledocholithiasis in these patients.

Regardless of whether ERCP is performed successfully, all patients with CCL will inevitably undergo second-step $\mathrm{LC}$ or one-stage CBDE+cholecystectomy [28]. Previous upper abdominal surgery, especially gastrectomy, is a relative contraindication for laparoscopic surgery [29]. In one study, all surgical failures were attributable to adhesions, which included adhesions to the anterior abdominal wall at the site of insertion of the initial trocar and adhesions around the gallbladder and CBD [30]. In our two hospitals, LC and LCBDE were first introduced in 1996 and 2008, respectively, and gained widespread clinical acceptance even in patients with a history of upper abdominal surgery. We adopted a preoperative intra-abdominal adhesion evaluation procedure in 2011 to anticipate the severity of intra-abdominal adhesions, and this evaluation procedure significantly reduced the conversion rate of LC in these patients as shown in our previous research $[7,8]$. In the present study, we chose the preoperative intra-abdominal adhesion evaluation score as a risk factor for conversion of LCBDE or performance of second-step $\mathrm{LC}$ in patients with CCL and a history of gastrectomy. We found that the success rates of laparoscopic surgery in patients with CCL and a history of gastrectomy are different when the preoperative intra-abdominal adhesion evaluation scores vary. When the evaluation score is $>3$ points in an individual patient, extensive intra-abdominal adhesions are suspected or present, and safe peritoneal access is therefore needed. Open laparoscopy is the most recommended method in these patients with Hasson cannula [31, 32]. The peritoneal access technique is not difficult, but it is essential to increase the success rate of initial trocar insertion. Therefore, comprehensive and accurate preoperative evaluation of the severity of adhesions is important, and application of this procedure to clinical treatment would help to reduce the conversion rate of laparoscopic surgery in these patients.

At last, we collected the clinical information of the patients who were performed $\mathrm{ERCP}+\mathrm{LC}$ or $\mathrm{LCBDE}+\mathrm{LC}$ successfully, and we found that the postoperative complications have no differences between two groups, but the hospital costs and length of hospital stay were reduced in LCBDE+LC group. These results accord with the previous research conclusions.

Although majority of carried out studies confirmed that the incidence of CCL after gastric resection is increased compared with the people without gastrectomy history, but performing prophylactic cholecystectomy during gastric cancer surgery is still being debated [33]. In the fact, according to the data from the available published literature, the incidence of gallstone formation and symptomatic cholecystolithiasis requiring cholecystectomy after gastrectomy is low [34]. Based on these observations, we believed that routine prophylactic cholecystectomy may not be necessary for all patients undergoing gastrectomy, but identify the risk factors which contribute to gallstone formation and subsequent cholecystectomy is really mattered and which can help surgeons to make their rational surgical treatment strategies and avoid subsequent surgery or surgical overtreatment.

Limitations and possible biases in this study are the lack of randomization, which may have caused some selection bias, and the small number of patients, making the detection of small differences between the study groups unreliable.

\section{Conclusions}

This study has shown that ERCP+LC seems to be an attractive strategy for treatment of CCL in patients with a history of Billroth I gastrectomy and that LCBDE+LC is suitable for patients with a history of Billroth II or Roux-en-Y esophagojejunostomy. Introduction of preoperative evaluation of intra-abdominal adhesions is beneficial for reducing the conversion rate of laparoscopic surgery in patients with CCL and a history of gastrectomy. 


\section{Abbreviations}

CBD: Common bile duct; CCL: Cholecystocholedocholithiasis;

ERCP: Endoscopic retrograde cholangiopancreatography; EST: Endoscopic sphincterotomy; LC: Laparoscopic cholecystectomy; LCBDE: Laparoscopic common bile duct exploration; MRCP: Magnetic resonance cholangiopancreatography; RR: Relative risk

\section{Acknowledgements}

We thank Angela Morben, DVM, ELS, from Liwen Bianji, Edanz Editing China (www.liwenbianji.cn/ac), for editing the English text of a draft of this manuscript.

\section{Funding}

This work was supported by The Medical and Health Platform Plan fund of Zhejiang Province (2015ZDA029) and The Medical and Health Technology Achievement project fund of Zhejiang Province (2017ZHO20), China.

\section{Availability of data and materials}

All the data are available without restriction. Researchers can obtain data by contacting the corresponding author.

\section{Authors' contributions}

MZ and QY designed the studies. WY, JX and JZhang performed data acquisition and analysis. XS and JZhu performed statistical analysis and data interpretation. MZ prepared the manuscript. All authors read and approved the final manuscript.

\section{Ethics approval and consent to participate}

This study was approved by the ethics committee of Huzhou central hospital (HzhcLS2017-123) and the NO.3 people's hospital of Changxing county (CxdsrmhLS2018-01), and the procedures were in compliance with Helsinki Declaration. Written informed consent forms about this procedure were obtained for all patients before surgery.

\section{Consent for publication}

Not applicable.

\section{Competing interests}

The authors declare that they have no competing interest.

\section{Publisher's Note}

Springer Nature remains neutral with regard to jurisdictional claims in published maps and institutional affiliations.

\section{Author details}

'Department of Hepatobiliary surgery, Huzhou Hospital, Zhejiang University School of Medicine (Huzhou Central Hospital), No. 198, Hongqi Road, Huzhou 313000, Zhejiang Province, China. 'Department of General surgery, The NO.3 People's hospital of Changxing County, No. 19, Tianneng Road, Changxing 313104, Zhejiang Province, China.

\section{Received: 24 May 2018 Accepted: 30 July 2018}

\section{Published online: 09 August 2018}

\section{References}

1. Vannijvel M, Lesurtel M, Bouckaert W, Houben B, Knol J, Vangertruyden G, Sergeant G. A survey of European-African surgeons' management of common bile duct stones. HPB (Oxford). 2016:18(12):959-64.

2. Quaresima S, Balla A, Guerrieri M, Campagnacci R, Lezoche E, Paganini AM. A 23 year experience with laparoscopic common bile duct exploration. HPB (Oxford). 2017;19(1):29-35.

3. Zheng C, Huang Y, Xie E, Xie D, Peng Y, Wang X. Laparoscopic common bile duct exploration: a safe and definitive treatment for elderly patients. Surg Endosc. 2016;

4. Podda M, Polignano FM, Luhmann A, Wilson MS, Kulli C, Tait IS. Systematic review with meta-analysis of studies comparing primary duct closure and Ttube drainage after laparoscopic common bile duct exploration for choledocholithiasis. Surg Endosc. 2016;30(3):845-61.

5. Lorusso D, Misciagna G, Noviello MR, Tarantino S. Cholelithiasis after Billroth II gastric resection. Surgery. 1988;103(5):579-83.
6. Hauters P, de Neve de Roden A, Pourbaix A, Aupaix F, Coumans P, Therasse G. Cholelithiasis: a serious complication after total gastrectomy. Br J Surg. 1988;75(9):899-900.

7. Zhang MJ, Yan Q, Zhang GL, Zhou SY, Yuan WB, Shen HP. Laparoscopic Cholecystectomy in Patients With History of Gastrectomy. Jsls-J Soc Laparoendoscopic Surgeons. 2016;20(4)

8. Zhang MJ, Cao LP, Ding GP. Successful laparoscopic common bile duct exploration in a patient with previous Billroth II gastrectomy. Int J Clin Exp Med. 2017;10(3):5480-5.

9. Chen Y, Li Y. Related factors of postoperative gallstone formation after distal gastrectomy: a meta-analysis. Indian J Cancer. 2017;54(1):43-6.

10. Liang TJ, Liu SI, Chen YC, Chang PM, Huang WC, Chang HT, Chen IS. Analysis of gallstone disease after gastric cancer surgery. 2017;20(5):895-903.

11. Paik KH, Lee JC, Kim HW, Kang J, Lee YS, Hwang JH, Ahn SH, Park DJ, Kim $\mathrm{HH}, \mathrm{Kim} \mathrm{J}$. Risk factors for gallstone formation in resected gastric Cancer patients. Medicine. 2016;95(15):e3157.

12. Cariati A, Piromalli E, Cetta F, Andorno E. Black or Brown pigment and cholesterol gallstones formation among patients that underwent gastrectomy for Cancer. World J Surg. 2017:41(10):2642.

13. Furukawa H, Ohashi M, Honda M, Kumagai K, Nunobe S, Sano T, Hiki N. Preservation of the celiac branch of the vagal nerve for pylorus-preserving gastrectomy: is it meaningful? Gastric can offic j Int Gastric Can Assoc Japanese Gastric Can Assoc. 2018;21(3):516-23.

14. Beal JM. Historical perspective of gallstone disease. Surg Gynecol Obstet. 1984;158(2):181-9.

15. Moutinho-Ribeiro P, Peixoto A, Macedo G. Endoscopic retrograde cholangiopancreatography and endoscopic ultrasound: to be one traveler in converging roads. GE Portuguese j gastroenterol. 2018;25(3):138-45.

16. Meseeha M, Attia M. Endoscopic retrograde cholangiopancreatography (ERCP). In: StatPearls, editor. . Treasure Island: StatPearls Publishing StatPearls Publishing LLC; 2018.

17. Bove A, Di Renzo RM, Palone G, Testa D, Malerba V, Bongarzoni G. Singlestage procedure for the treatment of cholecysto-choledocolithiasis: a surgical procedures review. Ther Clin Risk Manag. 2018;14:305-12.

18. Franceschi D, Brandt C, Margolin D, Szopa B, Ponsky J, Priebe P, Stellato T, Eckhauser ML. The management of common bile duct stones in patients undergoing laparoscopic cholecystectomy. Am Surg. 1993;59(8):525-32.

19. Petelin JB. Laparoscopic common bile duct exploration. Surg Endosc. 2003; 17(11):1705-15.

20. Singh AN, Kilambi R: Single-stage laparoscopic common bile duct exploration and cholecystectomy versus two-stage endoscopic stone extraction followed by laparoscopic cholecystectomy for patients with gallbladder stones with common bile duct stones: systematic review and meta-analysis of randomized trials with trial sequential analysis. 2018.

21. Vettoretto N, Arezzo A, Famiglietti F, Cirocchi R, Moja L, Morino M. Laparoscopic-endoscopic rendezvous versus preoperative endoscopic sphincterotomy in people undergoing laparoscopic cholecystectomy for stones in the gallbladder and bile duct. Surgical endoscopy. 2018;4:Cd010507.

22. Memon MA, Hassaballa H, Memon MI. Laparoscopic common bile duct exploration: the past, the present, and the future. Am J Surg. 2000;179(4):309-15.

23. Waage A, Stromberg C, Leijonmarck CE, Arvidsson D. Long-term results from laparoscopic common bile duct exploration. Surg Endosc. 2003;17(8):1181-5.

24. Wandling MW, Hungness ES, Pavey ES, Stulberg JJ, Schwab B, Yang AD, Shapiro MB, Bilimoria KY, Ko CY, Nathens AB. Nationwide assessment of trends in Choledocholithiasis Management in the United States from 1998 to 2013. JAMA Surg. 2016;151(12):1125-30.

25. Williams EJ, Green J, Beckingham I, Parks R, Martin D, Lombard M. Guidelines on the management of common bile duct stones (CBDS). Gut. 2008;57(7):1004-21.

26. Dasari BV, Tan CJ, Gurusamy KS, Martin DJ, Kirk G, McKie L, Diamond T, Taylor MA. Surgical versus endoscopic treatment of bile duct stones. Cochrane database systematic reviews. 2013;(12):Cd003327.

27. Lu J, Cheng Y, Xiong XZ, Lin YX, Wu SJ, Cheng NS. Two-stage vs singlestage management for concomitant gallstones and common bile duct stones. World J Gastroenterol. 2012;18(24):3156-66.

28. Nagaraja V, Eslick GD, Cox MR. Systematic review and meta-analysis of minimally invasive techniques for the management of cholecystocholedocholithiasis. J hepato-biliary-pancreatic sci. 2014;21(12):896-901.

29. Karayiannakis AJ, Polychronidis A, Perente S, Botaitis S, Simopoulos C. Laparoscopic cholecystectomy in patients with previous upper or lower abdominal surgery. Surg Endosc. 2004;18(1):97-101. 
30. Fraser SA, Sigman H. Conversion in laparoscopic cholecystectomy after gastric resection: a 15-year review. Canadian j surg I canadien de chirurgie. 2009;52(6):463-6.

31. Catarci M, Zaraca F, Mulieri G, Di Paola M, Montemurro L, Filippoussis P, Greco E, Gossetti F, Carboni M. Routine use of open laparoscopy: technique and results in 1006 consecutive cases. Chir Ital. 1999:51(2):151-8.

32. Karatassas A, Walsh D, Hamilton DW. A safe, new approach to establishing a pneumoperitoneum at laparoscopy. Australian New Zealand j surg. 1992; 62(6):489-91.

33. Kimura J, Kunisaki C, Takagawa R, Makino H, Ueda M, Ota M, Oba M, Kosaka T, Akiyama $\mathrm{H}$, Endo I. Is routine prophylactic cholecystectomy necessary during gastrectomy for gastric Cancer? Reply. World J Surg. 2017;41(10):2643.

34. Liang T-J, Liu S-I, Chen Y-C, Chang P-M, Huang W-C, Chang H-T, Chen IS. Analysis of gallstone disease after gastric cancer surgery. Gastric can offic $j$ Int Gastric Can Assoc Japanese Gastric Can Assoc. 2017;20(5):895-903.

Ready to submit your research? Choose BMC and benefit from:

- fast, convenient online submission

- thorough peer review by experienced researchers in your field

- rapid publication on acceptance

- support for research data, including large and complex data types

- gold Open Access which fosters wider collaboration and increased citations

- maximum visibility for your research: over $100 \mathrm{M}$ website views per year

At BMC, research is always in progress.

Learn more biomedcentral.com/submissions 